\title{
Developments in the UK: work of the Low Income Project Team
}

\author{
BY MICHAEL NELSON
}

Department of Nutrition and Dietetics, King's College London, Campden Hill Road, London W8 7AH

The Health of the Nation document published in 1992 (Department of Health, 1992) set in place a comprehensive strategy for promoting public health across the whole community. Of the priority key areas (coronary heart disease and stroke, cancers, mental and sexual health, and accidents) heart disease, stroke and cancers have a clear nutritional component. Specific targets were set in relation to dietary objectives. The Nutrition Task Force (NTF) was established to prepare an action programme aimed at achieving the dietary targets, and its first report, Eat Well, was published in 1994 (Department of Health, 1994).

The NTF recognized that people on low incomes may experience particular difficulties in constructing a healthy and varied diet in line with Health of the Nation targets. (Dowler \& Dobson (1997) in the present symposium have described the extent of the problem and its consequences in Britain and elsewhere in Europe.) The NTF established the Low Income Project Team (LIPT) to collate and disseminate examples of good local practice which might enable those on low income to ensure that they eat a healthy diet. The terms of reference of the LIPT were to collate examples of effective coping strategies and good local practice, to consider how to evaluate them, and to make recommendations concerning the best ways to improve access to healthy diets for low-income households. It was not within the remit of the LIPT to discuss the adequacy of benefit levels. One consequence of this restriction was to focus the Project Team's efforts on policy initiatives to improve dietary health in low-income households.

\section{THE LOW INCOME PROJECT TEAM REPORT}

The LIPT report, Low Income, Food, Nutrition and Health: Strategies for Improvement*, was published in April 1996 (Department of Health, 1996a) concurrently with the Eat Well II* report summarizing all the LIPT recommendations (Department of Health 1996b). Its principal strategic recommendations were:

to develop a co-ordinated national approach on food and low income;

to establish local food partnerships;

to set up a national network and database on food and low income.

The development of a co-ordinated national approach to the problems of food and low income requires the participation of all those agencies and organizations at national and local level whose actions influence access to, and availability of, food. A list of these agencies and some suggested actions is given in the Appendix. It is vital that the actions taken by the different agencies support and complement on another. A neutral forum for constructive dialogue between these agencies is needed in order to ensure that those whose interests may be seen to be competing (e.g. food retailers, whose shareholders want increased profits, $v$. low-income communities, who need food at the lowest possible prices) have voices which can be heard on an equal basis.

Local food partnerships require local authorities, food retailers, and low-income communities themselves to make joint decisions about the provision of a healthy and affordable food supply. Such partnerships recognize the wider issues concerning provision of food supply in a healthy society, over and above those dictated by market forces. These

*Available free from: Department of Health, PO Box 410, Wetherby LS23 7LN. Fax: 01937845381. 
include the right of citizens to have access to a safe, health-enhancing and affordable food supply (different from the consumer's right to buy what they can afford in a market over which they have no control), the interplay between local food economies and community employment, and links between public transport and public health (i.e. access to food shops). Partnerships should work toward the integration of the community projects (which, given the scale of the problem, cannot be expected to form a second tier of retailing) with mainstream retail food supply, for example, by encouraging transfer of skills from retailers to local food schemes, assisting with central buying and distribution, etc.

A national network and database provide opportunities for exchange of skills and information between projects, communities, local authorities, and other agencies. The aim is to stimulate and facilitate the development of projects and to encourage evaluation of their effectiveness in achieving both their own stated aims and the wider aims of the NTF. The National Food Alliance (NFA) has established a Food Poverty Network whose membership consists of local food project leaders and members, community development workers, academics, and many others. It publishes a newsletter, Let Us Eat Cake (National Food Alliance, 5-11 Worship Street, London EC2A 2BH), and arranges conferences for face-to-face opportunities for exchange of information. The NFA is also collaborating with the Health Education Authority to establish a database of projects to facilitate rapid access to information about how projects are set up and run, funded, and evaluated. Further activities of the NFA are described later (see p. 94).

\section{Constraints on action}

Local food projects provide valuable access to foods and skills which would not otherwise be available to the community. They cannot, however, be expected to address a problem which affects millions of people in Britain. They suffer from:

shortage or lack of funding, particularly for longer-term development; chaotic and confusing funding channels;

competition from discount retailers;

isolation of individual initiatives;

rural isolation;

difficulty in maintaining community involvement in management and development; information deficit; lack of support from relevant professionals; poor access to transport for stock delivery; reliance on volunteers; absence of tested methods for evaluating the success of community-based initiatives; lack of evaluation techniques which could help to provide feedback on project impact and evidence for continued support.

While a network and database will help to strengthen the actions being taken on a local basis, a clear and nationally-co-ordinated strategy is needed to integrate all players. There was no obvious forum in which this development could take place.

\section{Research needs}

The report recognized that in order to achieve its recommendations and provide a firm foundation for the development of policy, research is needed on the effectiveness of different approaches to the problems of food poverty. Evidence is lacking with which to convince local and national funding agencies of the benefits of action and the justification 
for support for local initiatives and partnerships. Because of the diversity of low-income communities, and the range of objectives that different communities may see as important, no single approach will satisfy all needs. The research aims embrace:

Evaluation of projects: in terms of process (how effective they are in achieving the project's stated aims), social outcomes (demographic characteristics of participants, shopping and meal patterns, intra-household food distribution, social interactions around food, changes in other non-food health behaviours (e.g. smoking)), and nutritional outcomes (changes in food consumption and nutrient intakes);

Indices of food availability and costs, to monitor strategies: a healthy basket index (variety, availability, access, costs); a green-shelf index (availability of fresh produce); a freshproduce-prices index; a food-deprivation index (an assessment of food vulnerability in a community); and a food-access index (relating to distances to shops, availability of public and private transport, opening hours, etc.);

Costs of a healthy diet: considerable work has been carried out to estimate the costs of a modest-but-adequate and healthy basket of food for a variety of household types (Family Budget Unit, 1995). Budget standards of this type are needed to inform realistic estimates of costs for social security payments. Other influences on costs (e.g. debt repayments, foodrelated benefits such as school milk) also need to be considered;

Impact tracking of the influences of social policy regarding food provision on medium- to long-term health outcomes;

Evaluation of a toolkit to help initiatives to become established.

\section{FORUM ON DIET AND HEALTH IN LOW-INCOME FAMILIES}

The LIPT ceased to exist as an official body once the report (Department of Health, 1996a) was published. Members of the LIPT believed, however, that no single agency amongst those listed in the Appendix was in a position to provide a neutral forum for the development of the co-ordinated national approach recommended in the report. The first necessary step in the development of a national strategy was to organize a meeting of the constituencies listed in the Appendix to discuss the way forward. Therefore, an ad hoc group of members of the LIPT organized a meeting. It was held at the Royal Society of Medicine under the auspices of the Forum on Food and Health (Nelson et al. 1996), as it was felt that this venue provided an appropriate neutral arena for frank and open discussion. This was the first time that representatives of national and local government departments, local community projects, food retailers, funding agencies (including the Research Councils), and academics met to discuss the way in which to take forward a coordinated national strategy. Approximately seventy participants attended the meeting. The objectives were to:

1. identify action already being taken and consider how it might be strengthened and added to;

2. identify barriers to progress and how they might be overcome;

3. discuss the nature of appropriate partnerships at both national and local level for delivering the improvements called for;

4. set an agenda to implement these partnerships and report back on their progress.

\section{Current action}

The first session provided an opportunity to review current activities.

National and local government. The Department of Health and Ministry of Agriculture Fisheries and Food (MAFF) regard the implementation of the recommendations of the 
LIPT as the responsibility of the public interest sector, the food industry and health professionals. Ministries will continue to monitor and evaluate changes in relation to lowincome groups, and try and ensure that policies embrace the needs of low-income households. Local Authorities described work on anti-poverty initiatives of which food and low income is a part. They saw as essential the establishment of a policy team on poverty and identification of a lead officer on food policy. Local Authorities are especially aware of the need for evidence to convince planners and funders that money spent on local food projects will produce tangible benefits for the communities concerned.

Producers and retailers. Numerous retailers described steps already taken to address the problems of low-income communities, including the appointment of a Community Affairs Manager (Kwiksave), economy ranges of foods (Sainsbury, Tesco and others), and recognition that siting shops outside of town centres is a problem for those without access to adequate public or private transport. Other organizations such as the National Farmers Union, the Meat and Livestock Commission, the National Dairy Council, and the Institute of Grocery Distribution described activities which embrace the concerns of low-income households.

Voluntary sector and public-interest groups. Food projects and partnerships have been established in many communities around the country, ranging in character from supplying food (co-ops and community cafés), to teaching cooking and budgeting skills and to facilitating communication between communities and policy makers. The work of the NFA in developing a national Food Poverty Network and Database has been described previously (p. 92). In addition, the NFA is currently evaluating many projects and developing a 'toolkit', a development of their pack on Food and Low Income (National Food Alliance, 1994), which is designed to assist project developers to establish, fund and evaluate projects. The Scottish Food Poverty Network described work on the development of a project on complementary retailing methods which are sustainable. The Public Health Alliance has identified a number of projects related to food and the improvement of public health.

Research bodies and academic activities. The Joseph Rowntree Foundation (JRF) has long supported research in the area of poverty, and has helped with wide dissemination of research findings in a format accessible to all groups (Dobson et al. 1994; Hills, 1995; Dowler \& Calvert, 1995). The training of public health nutritionists in academic institutions in the UK now addresses problems of poverty in industrialized countries, especially in relation to access to a healthy diet. Agencies such as the Institute of Food Research described research into more economically-efficient agricultural and food distribution practices, such as reduced losses of food through better packaging and farming practices, which should in theory help to keep food prices down.

\section{Building on current action}

Participants joined workshops to discuss how to develop current activities and partnerships. They identified a number of areas in which the issue of food in relation to low income needed to have a higher priority or more specific focus in order to ensure that action could be undertaken.

Raising awareness. Policy must first be clearly defined and then translated into action. The workshops provided opportunities for all the agencies involved in the development of co-ordinated strategy to identify further practical action, research and funding needs that would help increase access and affordability of healthy food to low-income groups. There is a need to move food higher up the political agenda both locally and nationally. Government Departments and Local Authorities need to develop clearly stated policy 
objectives which call for all decisions and legislation to be reviewed in relation to their effect on food supply to low-income households. Policy makers both inside and outside the Department of Social Security must discuss the adequacy of benefit levels, and use budget standards to calculate them. MAFF has a valuable role as a single ministry in which the whole of the food chain is represented, but reform is needed to resolve issues where the interests of consumers and producers conflict (e.g. bovine spongiform encephalopathy, transgenic animals and plants, etc.); to recognize the effects of the Common Agricultural Policy on low-income households; and to embrace the outcomes of European Union policies in which consumer interests are more strongly and independently represented.

Training and education. Employment, education, and training schemes need to be formulated to encourage participation in community food projects. Professionals such as general practitioners, local-authority planners, and others working with low-income communities need training in effective methods of communication and assessment of need, carried out in collaboration with the communities themselves. Home Economics must be made a core subject in the National Curriculum; domestic budgeting and cooking skills are too important to health to be left to families to provide. Already there is a vicious circle of de-skilling in which children from low-income households may never have opportunities to learn health-enhancing food practices.

Funding. Funding for projects must be long term. Dependencies build quickly, and communities in which projects start and finish within 1 year may be left worse off because an important resource is suddenly removed. Funding needs to provide for paid staff, as those who are unpaid are often unwilling to take on responsibility within projects. Franchising or 'sponsorship' of community shops should be explored through public and private channels. Biotechnology and Biological Science Research Council, Economic and Social Research Council and other funding bodies should not take decisions about funding priorities and appropriate areas for research on food and low-income without consulting the local communities concerning their needs and priorities.

Food partnerships. Food partnerships with the objective of increasing food supply were seen as essential and could take various forms:

community projects and/or dietitians working with retailers and local businesses; community groups working with local and national policy makers;

large and small retailers working together to exchange expertise and resources; community groups representing individual minority groups working with each other; community groups, local-authority planners and food retailers working together to improve retail facilities.

Research needs. The research needs identified reflected and expanded the list outlined in the LIPT Report (Department of Health, 1996a). More information is needed about practical initiatives that can be shown to work. Effectiveness indicators for community projects must be developed which are acceptable to funders and achievable by the projects (supported where appropriate by local academic and health professionals). This can lead to the development of model projects known to work. Lessons from abroad need to be considered in Britain, e.g. particular schemes in North America, such as the Women, Infants and Children Program. Work is needed on the health advantages of 'low-cost goodvalue' products, food acceptability and choice, indices of community food access and availability, budget studies to assess the adequacy of benefit levels and to set standards for affordable healthy food, the effects of macro-economics on the food business and the market's ability to supply healthy affordable food to all and on the effectiveness of the provision of information and dissemination. 


\section{Barriers to progress}

The first afternoon session was devoted to identifying factors that impede the development of policies or practices that would improve the access of low-income households to an affordable health-enhancing diet. This list differs somewhat from that given in the LIPT Report (Department of Health, 1996a) in that its emphasis was informed by a broad crosssection of participants with direct community roles in the alleviation of food poverty.

Some key factors included:

poor definition of the problem of 'food poverty' in Western countries, how it differs from that in developing countries, and the wider recognition by national and local government that people are citizens for whom food is a basic human right, not consumers who merely have the right to what they can afford;

lack of a national support strategy for local activity;

the physical and administrative distances between low-income communities and policy makers;

lack of local effectiveness indicators which need to be diverse and measurable by projects; the need for funding to be given for projects before their impact has been proven;

unwillingness to experiment with unproven methods;

vulnerability of projects due to lack of funding or provision of only short-term funding; the need for retailers to see themselves as a part of the community, and recognition that the physical distance between out-of-town supermarkets and low-income communities creates serious problems of access;

inefficient use of local resources such as schools which are empty for much of the year; deregulation of the market (e.g. reduction in business rate) to allow for more cost-effective marketing on low-income areas;

diversity of issues and needs amongst low-income groups;

lack of awareness among the general public of the impact of poverty;

recognition of the need for partnerships which cross public and private sector boundaries and embrace the diversity of problems which arise from the diversity of low-income communities.

\section{Moving forward: consensus and commitment}

The day concluded with a session devoted to the development of statements about specific activities in each of four constituency areas: local community projects, retailers, researchers, and pressure groups. There was clear commitment and consensus from all groups that the work of the LIPT must continue via a cross-sectoral forum which should consist of representatives from the four groups mentioned plus national and local government. The follow-up meeting was held in December 1996.

All groups agreed to build on the manifest concern that further work is needed to increase access of low-income groups to affordable healthy food and to reduce social exclusion.

Local Projects want:

to form networks at a local level but have access to a national forum;

local communities to set their own agenda;

to liaise and develop partnerships with retailers;

help with research into community needs, the effectiveness of local projects, and dissemination of the findings;

to work with pressure groups who can lobby for change at a national level. 


\section{Retailers want:}

to involve the whole food industry and collect their views;

to work with the local community to meet their needs;

a research base to identify what industry could achieve;

to keep in close contact with other relevant groups.

Researchers want:

a national forum that cuts across the existing research groupings and is not central to one funding agency's remit;

to provide a forum for information exchange and be available to give advice on research methods, areas of work and dissemination of results in an accessible format.

Pressure groups want:

a common forum to carry on the work of the LIPT;

to broaden the focus of the work of the forum to include benefit levels;

to monitor action on the recommendations made at the 1996 World Food Summit which will require funding and a research capability.

There was also awareness at the end of the meeting that a national and local government group was needed to help define their requirements.

\section{A WAY FORWARD}

The work of the LIPT and the subsequent meeting in May have focused awareness on the failure of the food supply system in Britain to provide a healthy balanced diet which is within everyone's financial reach and cultural norms. The present symposium provides an opportunity to think about how to direct the conclusions of nutritional science regarding food, health and poverty towards a (non-party) political agenda which must represent a consensus for action. We can combine a sense of scientific objectivity with a sense of political redress.

We must conclude that the present British food-retailing system which has been driven largely by market forces and shareholders' interests is no longer a valid model if we are to address the diet-related health problems of the poor. There must be an element of social responsibility in food retailing which includes the health of society and participation in the community as appropriate goals. As scientists, we are called upon to provide the information which relates diet, poverty and health in order to demonstrate the need for a social element in retailing. Part of that evidence relates inevitably to decisions about shop siting, stocking, pricing structures and transport which result in large numbers of households being effectively deprived of an affordable and healthy food supply.

At the turn of the century, Rowntree developed a model of industrial and community interaction in which there was direct feedback: improved sanitation and health care in a purpose-built village resulted in better factory production and a happier work-force, creating a virtuous circle of better health and increased production. It was a form of benign capitalism more than a welfare system, combining elements of health, education, and basic income with sustainable profits. We are now faced with a different model in which the direct needs of local communities are subsumed by the needs of shareholders. If it is not profitable for a retailer to maintain a shop in a particular community, then for the sake of the shareholders (who are likely to live elsewhere) the shop is closed. This action can be taken regardless of the consequences for the local community.

It is not acceptable, in my view, to allow the dietary health of communities to be determined in this way. We need to consider the right of citizens to a healthy and affordable food supply. This view differs fundamentally from the consumer model which 
says that people have choice within the resources available. For low-income households, such choice does not exist if they live in communities in which the only fresh fruit is 2 miles away by bus and costs $£ 2.00$ to get to.

The terms of reference of the LIPT specifically excluded discussion of the adequacy of benefit levels. This begs the question of whether they are indeed adequate. The answer is clearly 'No, they are not' (Nelson et al. 1993). We must, therefore, provide an alternative model of food retailing which addresses the needs of the poorest $25 \%$ of households whose dietary requirements are not presently being met. These include households on low incomes, not just those receiving benefits.

The models proposed by the LIPT (Department of Health, 1996a) and elaborated by the Forum on Food and Health (Nelson et al. 1996) and other agencies provide a foundation for the development of a new food-retailing system which brings community needs into the decision-making process. They are set in a context of education and skills training. There is also a short-term requirement to develop alternative schemes for food provision where the market system is currently failing. There is at present a strong will to develop these structures and to ensure that all the constituent players (government, retailers, pressure groups, researchers, and the communities themselves) share in their development. We must seize this opportunity.

\section{REFERENCES}

Department of Environment (1994). Homelessness: Code of Guidance for Local Authorities. London: H.M. Stationery Office.

Department of Health (1992). Health of the Nation. London: H.M. Stationery Office.

Department of Health (1994). Eat Well. London: H.M. Stationery Office.

Department of Health (1996a). Low Income, Food, Nutrition and Health: Strategies for Improvement. London: H.M. Stationery Office.

Department of Health (1996b). Eat Well II. London: H.M. Stationery Office.

Dobson, B., Beardsworth, A., Keil, T. \& Walker, R. (1994). Diet, Choice and Poverty: Social, Cultural and Nutritional Aspects of Food Consumption Among Low Income Families. Loughborough University of Technology: Centre for Research in Social Policy.

Dowler, E. A. \& Dobson, B. M. (1997). Nutrition and poverty in Europe: an overview, Proceedings of the Nutrition Society 56, 51-62.

Dowler, E. \& Calvert, C. (1995). Nutrition and Diet in Lone-parent Families in London. London: Family Policy Studies Centre.

Family Budget Unit (1995). Modest but Adequate. Household Budgets for Sixteen Households, October 1994 Prices. London: Family Budget Unit.

Hills, J. (1995). Inquiry into Income and Wealth. vol.2. York: Joseph Rowntree Foundation.

National Food Alliance (1994). Food and Low Income: A Practical Guide for Advisors and Supporters Working with Families and Young People on Low Incomes. London: National Food Alliance.

Nelson, M., Dowler, E. A. \& Cottee, P. (1996). Tackling the problems of diet and health in low income families: Summary of the proceedings of a Food and Health Forum held on 14 May 1996 at the Royal Society of Medicine. London: King's College.

Nelson, M., Mayer, A. B. \& Manley, P. (1993). The food budget. In Budget Standards for the United Kingdom, pp. 101-120 [J. Bradshaw, editor]. Aldershot, Hants: Avebury.

\section{APPENDIX: KEY PLAYERS IN THE DEVELOPMENT OF A CO-ORDINATED NATIONAL APPROACH TO PROBLEMS OF FOOD AND LOW INCOME: PRIORITIES FOR ACTION (FROM DEPARTMENT OF HEALTH, 1996a)}

National agencies

Department of Health (including NHS Executive)

Develop proposals for action to improve nutritional health in lowincome households

Evaluate projects and promote research to improve nutritional health in low-income households 
Department of the Environment

Department for Education and Employment

Department of Social Security

Ministry of Agriculture, Fisheries and Food (MAFF)

Inland Revenue

Health Education Authority

Institute of Grocery Distribution (IGD)

Food retailers

Networks
Take immediate action to initiate a forum to develop a strategy to co-ordinate social policies on food and low income

The NHS Executive should provide appropriate planning priorities and guidance for health authorities relating to nutritional health in low-income households

Provide guidelines to Local Authorities for planning relating to food supply in light of the impact on low-income households. These should inform the priorities of Community Development programmes and 'City Challenge' initiatives

A revitalization of allotments, and a reassertion by Government of the value of growing one's own food, which could be both popular and health-enhancing. This should be carried out in collaboration with MAFF

Maintain a place for food and nutrition in the curriculum. This will have the greatest benefit in areas where food and low income is likely to have an adverse effect on both short-term and long-term health

Support the introduction of voluntary guidelines for the nutritional quality of school meals being proposed by the NTF School Meals Project Team

Benefits Agency, with others (including domestic-fuel suppliers), to participate in a national programme to ensure that account is taken at the local level of the absolute requirement for adequate cooking facilities and domestic fuel supply

Encouragement of regional experiments in farmers' markets, where growers are encouraged to come into towns to sell produce direct. We welcome MAFF's recent interest in such schemes

Exemption of money gained from selling home-grown produce from earnings declaration, which could have a particular advantage for rural households on low income and those in LETS schemes

To provide a key contact point for a wide range of health promotion resources

To support qualitative and quantitative research on health especially in relation to low-income households

The Social Responsibility Group within IGD should continue to encourage discussion amongst major food retailers on the impact on low-income households of store location, provision of food in rural and low-income urban areas, labelling, pricing, and the use of sub-titles in food advertising

Act at Board level to allow local shops to meet better the needs of low income households through shop siting, pricing flexibility, provision of transport, etc.

The NFA Food Poverty Network has been described on p. 92 
Voluntary and pressure groups

\section{Local agencies}

Local

Authorities

Health

Commissions
Many pressure groups (e.g. National Children's Homes, Child Poverty Action Group, Maternity Alliance), some of whom already have poverty on their agendas, should be encouraged to continue to contribute positively to discussions, in addition to their campaigning activities

Develop initiatives to help low-income households e.g. Health Alliances for food

Ensure that in meeting the statutory responsibilities to consult the community, the specific needs of low-income households are fully recognized

Support projects to improve nutritional health in low-income households

To take account of the Code of Guidance for Local Authorities (Department of Environment, 1994) in ensuring adequate access to cooking facilities and equipment for families in bed-andbreakfast accommodation

Locally, Departments of Public Health should identify individuals who have specific responsibility for matters relating to nutritional health, particularly in low-income households. 'Purchasers' should purchase advice about how to meet the needs of lowincome households, and fund studies as appropriate Include food problems of low-income households on education and training courses

Health Commissions Set up and use Joint Consultative Commissions to promote dialogue and Local Authorities between Local Authorities and Health Authorities concerning problems of food and low income

Local food projects

These projects include food co-ops, cookery courses, healthy-recipe leaflet development, community cafés selling cheap healthy foods, food and nutrition education courses, meal provision for those with special needs, food coupons, etc.

Schools

Make school facilities accessible to allow projects such as community cafés, cookery courses, or food-tasting sessions to be provided at least cost

Explore the introduction of School Breakfast programmes

Researchers and academics

Can help to develop local and national indicators and contribute effectively to local groups and partnerships

'White goods' manufacturers should be encouraged to donate food purée gadgets or 'money off' vouchers to aid purchase, to women in maternity wards, together with encouragement to make their own baby foods safely

NHS, National Health Service; NTF, National Task Force; LETS, Local Exchange and Trading Scheme; NFA, National Food Alliance. 